\title{
Soil heat flux and day time surface energy balance closure at astronomical observatory, Thiruvananthapuram, south Kerala
}

\author{
M S Roxy ${ }^{1, *}$ V B Sumithranand ${ }^{2}$ and G RenukA ${ }^{3}$ \\ ${ }^{1}$ Department of Physics, Sree Narayana College, Kollam-1, Kerala, India. \\ ${ }^{2}$ Govt. Higher Secondary School, Kulathoor, Thiruvananthapuram 695 583, India. \\ ${ }^{3}$ The Kerala State Council for Science, Technology and Environment (KSCSTE), \\ Sasthra Bhavan, Thiruvananthapuram 4, India. \\ *Corresponding author.e-mail: roxyms@gmail.com
}

Soil heat flux is an important input component of surface energy balance. Estimates of soil heat flux were made in the year 2008 using soil temperature data at Astronomical Observatory, Thiruvananthapuram, south Kerala. Hourly values of soil heat flux from 00 to 24 LST are presented for selected days typical of the winter, pre-monsoon, SW monsoon and NE monsoon seasons. The diurnal variation is characterized by a cross-over from negative to positive values at $0700 \mathrm{~h}$, occurrence of maximum around noon and return to negative values in the late evening. The energy storage term for the soil layer $0-0.05 \mathrm{~m}$ is calculated and the ground heat flux $G^{*}$ is estimated in all seasons. Daytime surface energy balance at the surface on wet and dry seasons is investigated. The average Bowen's ratio during the wet and dry seasons were 0.541 and 0.515 , respectively indicating that considerable evaporation takes place at the surface. The separate energy balance components were examined and the mean surface energy balance closure was found to be 0.742 and 0.795 for wet and dry seasons, respectively. When a new method that accounts for both soil thermal conduction and soil thermal convection was adopted to calculate the surface heat flux, the energy balance closure was found to be improved. Thus on the land surface under study, the soil vertical water movement is significant.

\section{Introduction}

Soil heat flux represents the amount of radiant energy absorbed or released at the soil surface during a given time period. Many field studies in topics such as microclimatology and hydrology require reliable measurements of the soil surface flux (Payero et al. 2005; Oladosu et al. 2007). Soil heat flux is a critical component of the surface energy balance along with the net radiation $(R)$, latent heat flux $(L)$, sensible heat flux $(H)$, and in some cases, canopy storage and photosynthesis
(Cobos and Baker 2003). The influence of soil heat flux on chemical reactions and microclimate are self evident. On a wet or full-vegetation-covered surface, the soil heat flux is of the same order as the sensible heat flux. For dry soil surfaces, the soil heat flux could be up to $50 \%$ of the net radiation. Even within a forest, the soil heat flux represents 30-50\% of the net radiation (Hsieh et al. 2009).

The radiant energy of the Sun is the only ultimate source of energy for all physical and biological processes occurring on the Earth and its atmosphere. The balance of energy at the Earth's

Keywords. Soil heat flux; surface energy balance; Bowen's ratio; sensible and latent heat fluxes. 
surface is inextricably linked to the overlying atmospheric boundary layer (Viswanadham 1972; Garratt 1992). The evapo-transpiration process depends upon, besides other factors, the availability of heat to satisfy the latent heat requirements. Numerous studies have been made to investigate the nature of radiation balance at the surface. Many of them are confined to the solar and infra-red radiation components. Much less is known about the absorption and conduction of heat by the soil and the exchange of heat between the soil and the atmosphere. Growth, development, and yield of field crops are largely governed by the complex interaction between the energy and water balance in the crop's immediate environment (Chowdhury et al. 1993). In soil-plant-atmosphere system, the energy balance equation is given by

$$
R=G^{*}+L+H
$$

where $G^{*}$ is the soil heat flux at the surface, $R$ is the net radiation, $L$ is the latent heat flux, and $H$ is the sensible heat flux. The ground heat flux is of considerable magnitude as the latent heat flux and thus constitutes an important term in the surface energy balance (Langer et al. 2011). The generally practiced neglect of the soil heat flux term in the energy balance equation is not agronomically justified in view of associated sub-soil migration of moisture. Soil heat flux is difficult to measure because it includes conduction and convection heat transfer processes (Heitman et al. 2010). Measurement or prediction of evaporation is often of great interest as it relates to studies of water balance and water management in agriculture. Soil heat flux, as a component of available energy, is a necessary input for many evaporation measurements and prediction techniques. Evaporation measured with the Bowen ratio energy approach is dependent on an accurate value for the available energy $(R-G)$.

The objective of this study is to estimate soil heat flux in the year 2008 using soil temperature collected at various depths using hydrometeorological data acquisition system. It is also intended to study the diurnal variation of soil heat flux in winter, pre-monsoon, SW monsoon and NE monsoon seasons. The diurnal variation of heat flux is influenced by soil moisture and incoming solar radiation. In dry days the net flow of heat is directed into the soil and in rainy days the reverse takes place. In this study, soil heat flux computed for monsoon period is found to be lower than that of winter and pre-monsoon periods indicating the influence of soil moisture in controlling the flow of heat within the soil. Results show that soil heat flux diurnally changed in shallow layers and diurnal variation strengths weakened with increase in depth. Seasonal changes in the soil heat flux also affect the surface energy budget. Daytime surface energy balance at the surface on wet and dry days is investigated. The average Bowen's ratio during the wet and dry days was estimated. It is also intended to examine the separate energy balance components, viz., net radiation, soil heat flux, latent heat flux, and the sensible heat flux, and to find the day time energy balance closure. An improved soil heat flux measurement method is used in the energy balance equation to achieve the day time energy balance.

\section{Site and data}

The study was conducted at Astronomical Observatory $\left(76^{\circ} 57^{\prime} \mathrm{E} ; 8^{\circ} 30^{\prime} \mathrm{N}\right)$, University of Kerala, adjacent to India Meteorological Department, Thiruvananthapuram in south Kerala. It is situated at about $64.31 \mathrm{~m}$ above mean sea level and nearly $8.4 \mathrm{~km}$ inland from coast. The climate of Kerala is tropical maritime and monsoonal in character. In fact the first burst of the southwest monsoon over the Indian subcontinent takes place over Kerala. The main rainy seasons in the state are south-west (SW) monsoon (June-September) and north-east (NE) monsoon (October and November). The pre-monsoon months (MarchMay) account for major thunderstorm activity in the state and winter months (December-February) are notable by minimum rainfall. June and July are the rainiest months while January and February receive the least rainfall. The seasonwise rainfall over Kerala indicated that a major part of the annual rainfall is received during south-west monsoon followed by north-east monsoon. The least is seen in winter (Menon and Rajan 1989; Prasada Rao 2003).

Kerala comes under iso-hyperthermic temperature regime (Chacko and Renuka 2008) which means that annual soil temperature is $22^{\circ} \mathrm{C}$ or higher and mean soil temperature of June-August and December-February differ by less than $5^{\circ} \mathrm{C}$ at a depth of $50 \mathrm{~cm}$ or at lithic or paralithic contact whichever is shallower. The colour of the soil at the experimental site varies from dark brown to dark reddish brown as we go to the deeper layers. Correspondingly, the soil texture varies from gravelly sandy loam to gravelly clay loam. The clay increase in sub-surface layers qualifies these soils to be placed under ultisols. The experimental site belongs to soils of laterite landscape developed under tropical climate with alternate wet and dry seasons.

Hourly soil temperatures on 20 randomly selected days from each season in 2008 obtained 
using hydro-meteorological data acquisition system installed at Astronomical Observatory, Thiruvananthapuram, south Kerala were used to study the diurnal variation in soil heat flux for three soil layers, $0-0.05,0-0.10$ and $0-0.20 \mathrm{~m}$. The days selected for the study are DOY $62-68$ and DOY 129-141 during pre-monsoon, DOY 20-31 and DOY $47-54$ during winter, DOY $172-179$, DOY 215-218, and DOY 266-273 during SW monsoon and DOY 288-300 and DOY 323-330 during NE monsoon. The rainfall and cloud cover data were collected from India Meteorological Department (IMD), Thiruvananthapuram, adjacent to the site under study. Unfortunately data for the month of April 2008 is missing due to technical reasons.

The sensing element for soil temperatures is $\mathrm{P}-\mathrm{N}$ junction semiconductor with fast response designed for continuous and long term measurements at soil depth. It is encased inside a stainless steel cover filled with silicon for better thermal conductivity and also to withstand the high geostatic pressure and rough handling in the field. A principle based on soil impedance is employed to sense the soil moisture directly from soil depths. Here the sensor is excited with sinusoidal signals of a selected and fixed frequency for eliminating electrical polarization and hence obtain a long term consistency in performance. The sensor associated with its signal conditioning, processed with embedded software eliminates the inherent non-linearity in its performance (Sivadas 2007). Both incident and reflected solar radiation sensors are developed using wide spectrum photodiodes. The accuracy, resolution and range of the sensors used in the hydro-meteorological data acquisition system are presented in table 1. Analog-to-digital converter (ADC) with 12 bits resolution, $1000 \mathrm{~KB}$ of nonvolatile memory, built-in real time clock, suitable for single analogous channel for multiplexing up to 256 channels, RS232 port for feeding data to computer is used for data storage. Software supports downloading data to computer and display of data of all channels in real time. The instruments have been tested and calibrated at regular intervals by the manufacturers (Environmental Measurements and Controls, Cochin). The data is compared with imported and good performance types available with Central Institute of Fisheries Technology (CIFT), Cochin and Rubber Research
Institute of India (RRII), Kottayam. All the sensors have good linearity and sensitivity which is approved by the calibration certificate of IMD, Pune.

\section{Method}

\subsection{Soil heat flux}

Soil heat flux is estimated from soil temperature profile measurements (Horton and Wierenga 1983). Liebethal and Foken (2007) reported that the approach of calculating soil heat flux from diurnal soil surface temperatures delivered satisfactory day time results. Using the temperature gradient method, soil heat flux is calculated from

$$
G=\lambda \frac{\left(T_{0}-T_{z}\right)}{\Delta z}
$$

where $\lambda$ is the thermal conductivity of the soil, $T_{0}$ and $T_{z}$ are the upper and lower soil temperatures of the top layer and $\Delta z$ is the width of the layer.

The thermal conductivity is calculated from the thermal diffusivity $(k)$ as:

$$
\lambda=k C_{s}
$$

where $C_{s}$ is the volumetric heat capacity.

The ground heat flux $\left(G^{*}\right)$ can be written as:

$$
G^{*}=G+\Delta S
$$

where $\Delta S$ is the energy storage term.

The energy storage term is calculated using the relation (Braud et al. 1993),

$$
\Delta S\left(\frac{t_{j}+t_{j-1}}{2}\right)=C_{s} \sum_{i=1}^{N} \frac{T_{i, j}-T_{i, j-1}}{t_{j}-t_{j-1}}\left(z_{i}-z_{i-1}\right)
$$

where $i$ and $j$ are index variables for depth layers and time steps, respectively.

Gao et al. (2003) incorporated thermal conduction and convection equations to consider the conduction and convection processes in the soil together as follows:

$$
\frac{\partial T}{\partial t}=k \frac{\partial^{2} T}{\partial z^{2}}+W \frac{\partial T}{\partial z}
$$

where $W$ is the liquid water flux density or convective velocity and $k$ is the soil thermal diffusivity.

Table 1. Specifications of the sensors used in the hydro-meteorological data acquisition system.

\begin{tabular}{lllll}
\hline Weather element & \multicolumn{1}{c}{ Sensor } & Resolution & Accuracy & Range \\
\hline Soil temperature & PN junction semiconductor & $0.1^{\circ} \mathrm{C}$ & $\pm 0.1^{\circ} \mathrm{C}$ & $0-60^{\circ} \mathrm{C}$ \\
Soil moisture & Stainless steel conducting rods & $0.1 \%$ & $\pm 0.2 \%$ & $0-50 \%$ \\
Solar radiation (incident and reflected) & Wide spectrum photodiode & $1 \mathrm{~W} / \mathrm{m}^{2}$ & $\pm 1 \mathrm{~W} / \mathrm{m}^{2}$ & $0-1500\left(\mathrm{~W} / \mathrm{m}^{2}\right)$ \\
\hline
\end{tabular}


Based on equation (6), Gao (2005) showed that in moist and tropical site soils, a third term that accounts for the thermal convection should be included so that the ground heat flux becomes:

$$
G^{*}=G+\Delta S+C_{w} \Delta T
$$

where $C_{w}$ is the water volumetric heat capacity and its value is chosen from Garratt (1992).

\subsection{Sensible and latent heat fluxes}

The sensible and latent heat fluxes are calculated using the relations (DeBruin and Holtslag 1982)

$$
\begin{gathered}
L=\left[\frac{\alpha^{\prime} s}{s+\gamma}\right]\left(R-G^{*}\right)+\beta^{\prime} \\
H=\left[1-\frac{\alpha^{\prime} s}{s+\gamma}\right]\left(R-G^{*}\right)-\beta^{\prime}
\end{gathered}
$$

where $\alpha^{\prime}$ is the modified Priestley-Taylor parameter. Its mean value in normal and dry periods are 0.95 and 0.65, respectively (DeBruin 1982; DeBruin and Holtslag 1982; Kumari and Sharma 1987; Abraham and Renuka 2005). The first term on the right hand side represents the contribution to the latent heat flux as a result of the heat supplied directly from the radiative flux. The second term $\beta^{\prime}$ is a constant, which accounts for the contribution due to the vapour pressure and the effects of surface and aerodynamic resistances. The values of $\beta^{\prime}$ are $35 \mathrm{Wm}^{-2}$ for pre-monsoon, 30 $\mathrm{Wm}^{-2}$ for winter, and $25 \mathrm{Wm}^{-2}$ for monsoon. Also, $\gamma$ is the thermodynamic value of the psychrometric constant equal to 0.066 and $s$, the slope of the saturation vapour pressure versus temperature curve. Equations (8) and (9) were used to estimate Bowen' ratio $B$ as:

$$
B=\frac{H}{L}
$$

\section{Results and discussion}

\subsection{Diurnal and seasonal variation of subsoil heat flux}

Twenty days from each season, pre-monsoon, winter, south-west (SW) monsoon and north-east (NE) monsoon were randomly selected to study the diurnal variation of soil heat flux. For comparison, diurnal variation of mean soil heat flux for each season is shown in figures 1 and 2. Mean hourly soil heat flux from 00 to $24 \mathrm{LST}$ for the soil layers, $0-0.05,0-0.10$ and $0-0.20 \mathrm{~m}$ are shown in each figure. Soil heat flux is regarded as positive when it
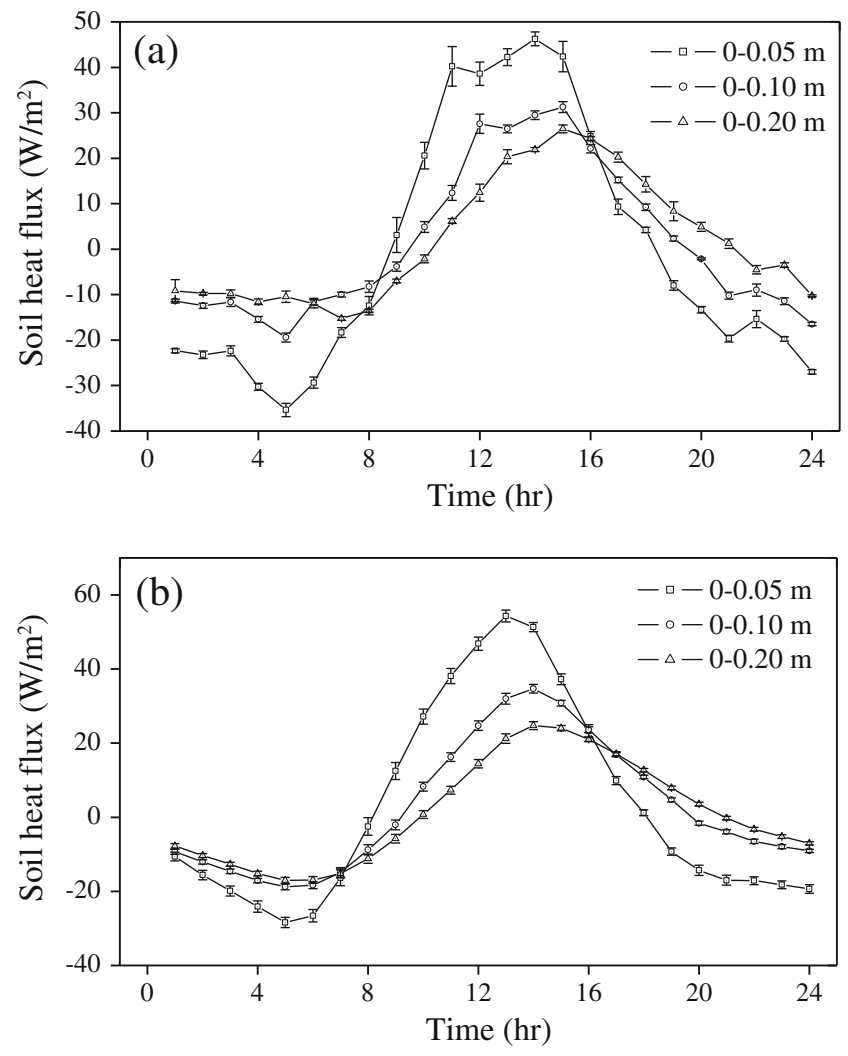

Figure 1. Diurnal variation of mean soil heat flux at three different depths on (a) during NE monsoon, 2008 and (b) SW monsoon, 2008.
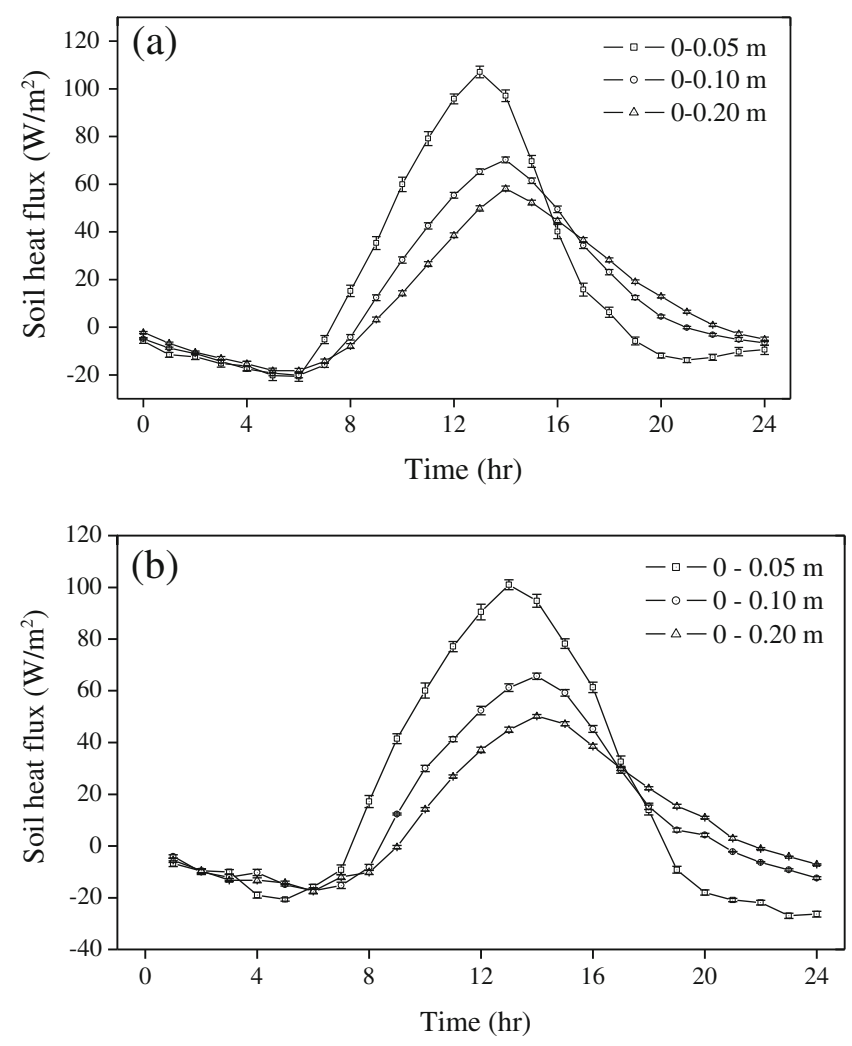

Figure 2. Diurnal variation of mean soil heat flux at three different depths during (a) pre-monsoon 2008 and (b) winter 2008 . 
is directed into the soil and negative in the opposite direction.

The diurnal variation of soil heat flux at the site is characterized by a cross-over from the negative to positive values around sunrise, occurrence of maximum during the hour ending at local noon and a return to negative values after sunset. However, the diurnal range of soil heat flux, and hence the $24 \mathrm{~h}$ sum, varies considerably with season. This is the combined effect of the solar radiation received by the surface and the moisture status of the soil. Here, the former alters the soil temperature profile whereas the latter regulates the values of thermal conductivity $\lambda$ (Kelkar et al. 1980). Table 2 shows the mean soil moisture (percentage by wt) at various depths and the corresponding standard deviation on the selected days for study. As expected, soil moisture is found to be high during the two monsoon seasons. The mean soil moisture is higher for deeper layer than the surface layer due to the rapid evaporation of soil moisture from the surface layer. The soil also supports water movement to the deeper layers.

Out of the two monsoon cases, the days selected from NE monsoon season were marked by almost continuous rain (figure 1a). Mean hourly soil heat flux on this day could reach a value of only 46.25 $\mathrm{Wm}^{-2}$ with a standard deviation of $6.82 \mathrm{Wm}^{-2}$ for the layer $0-0.05 \mathrm{~m}$ in the noon hour. The mean diurnal amplitude was $40.81 \mathrm{Wm}^{-2}$ for the layer 0 $0.05 \mathrm{~m}$ and the amplitude of the heat flux decreases as the depth increases. The mean of the $24 \mathrm{~h}$ sum for the day is $-24.97 \mathrm{Wm}^{-2}$ which means the overall flow of heat is from the soil to the atmosphere. Considerable variation in soil heat flux is also observed in the layer $0-0.05 \mathrm{~m}$ as compared to the other two layers. It is also seen that the diurnal trend is not smooth due to continuous rainfall. The soil heat flux reached $-35.35 \mathrm{Wm}^{-2}$ during early morning hours. The diurnal amplitude and daily total of soil heat flux at various soil layers during all seasons and the corresponding standard deviations are given in table 3 .
Again, during SW monsoon (figure 1b), the mean soil heat flux reaches a maximum value 54.31 $\mathrm{Wm}^{-2}$ with a standard deviation of $7.20 \mathrm{Wm}^{-2}$ which is a little higher than that of NE monsoon. The negative value of mean soil heat flux reaches a maximum of $-28.40 \mathrm{Wm}^{-2}$ in the early morning hours and the corresponding standard deviation is $6.08 \mathrm{Wm}^{-2}$. Most of the days selected during SW monsoon were non-rainy so that comparatively higher soil heat flux is observed. Also the diurnal curve is smooth when compared to NE monsoon season. The mean diurnal amplitude was 41.36 $\mathrm{Wm}^{-2}$ for the layer $0-0.05 \mathrm{~m}$ and the amplitude of the heat flux decreases to 26.74 and $20.88 \mathrm{Wm}^{-2}$ for the layers $0-0.10$ and $0-0.20 \mathrm{~m}$, respectively. The corresponding standard deviations are given in table 3. The mean $24 \mathrm{~h}$ sum for the day is $62.66 \mathrm{Wm}^{-2}$ indicating a net flow of heat into the soil. But negative value of heat flux is predominant

Table 3. Mean daily total and amplitude of diurnal soil heat flux and standard deviation at various depths.

\begin{tabular}{lccccc}
\hline \multirow{2}{*}{ Season } & Soil layer & \multicolumn{4}{c}{ Soil heat flux $\left(\mathrm{W} / \mathrm{m}^{2}\right)$} \\
\cline { 3 - 6 } SW monsoon & Surface & 71.35 & 42.61 & 59.45 & 5.77 \\
& $0-0.05$ & 62.66 & 34.95 & 41.36 & 4.98 \\
& $0-0.10$ & 57.97 & 32.67 & 26.74 & 3.65 \\
& $0-0.20$ & 27.14 & 16.40 & 20.88 & 2.89 \\
NE monsoon & Surface & -40.61 & 23.80 & 49.55 & 5.14 \\
& $0-0.05$ & -24.97 & 16.78 & 40.81 & 4.67 \\
& $0-0.10$ & 27.66 & 14.39 & 25.34 & 3.82 \\
Pre-monsoon total & SD & Amplitude & SD \\
\cline { 2 - 6 } & $0-0.20$ & 41.74 & 21.73 & 20.85 & 3.48 \\
& Surface & 474.32 & 77.38 & 95.83 & 8.88 \\
& $0-0.05$ & 456.21 & 68.96 & 63.89 & 7.46 \\
& $0-0.10$ & 333.32 & 59.23 & 45.20 & 5.51 \\
Winter & $0-0.20$ & 280.32 & 48.01 & 38.19 & 4.87 \\
& Surface & 481.24 & 69.67 & 88.85 & 7.99 \\
& $0-0.05$ & 453.53 & 66.01 & 64.00 & 6.90 \\
& $0-0.10$ & 299.81 & 58.56 & 41.45 & 4.82 \\
& $0-0.20$ & 232.59 & 46.59 & 33.84 & 4.19 \\
\hline
\end{tabular}

Table 2. Mean soil moisture (\%) and standard deviation at various depths on different seasons.

\begin{tabular}{|c|c|c|c|c|c|c|c|c|}
\hline \multirow[b]{3}{*}{ Depth (m) } & \multicolumn{8}{|c|}{ Soil moisture (\%) } \\
\hline & \multicolumn{2}{|c|}{ Winter } & \multicolumn{2}{|c|}{ Pre-monsoon } & \multicolumn{2}{|c|}{ SW monsoon } & \multicolumn{2}{|c|}{ NE monsoon } \\
\hline & Mean & $\mathrm{SD}$ & Mean & SD & Mean & SD & Mean & $\mathrm{SD}$ \\
\hline 0.05 & 12.96 & 0.98 & 13.37 & 1.02 & 33.12 & 1.73 & 35.93 & 1.84 \\
\hline 0.10 & 13.07 & 0.69 & 14.28 & 0.86 & 33.55 & 0.98 & 40.49 & 1.39 \\
\hline 0.20 & 16.69 & 0.93 & 15.98 & 0.63 & 38.44 & 1.35 & 40.86 & 1.41 \\
\hline 0.30 & 17.02 & 0.58 & 19.67 & 0.94 & 38.67 & 1.03 & 41.33 & 0.93 \\
\hline 0.50 & 22.13 & 0.49 & 25.18 & 0.59 & 41.42 & 0.42 & 41.86 & 0.68 \\
\hline
\end{tabular}

SD - standard deviation. 
during night and early morning hours. In monsoon seasons, soil heat flux is seen to change its flow direction around $8 \mathrm{~h}$ in the morning and after $18 \mathrm{~h}$ in the evening.

In contrast to the two monsoon seasons, the diurnal curves of mean soil heat flux in the pre-monsoon and winter season exhibit a clearly defined maximum around local noon and have regular and symmetrical shape. In the pre-monsoon season (figure 2a), the mean diurnal amplitude of the soil heat flux for the soil layer $0-0.05 \mathrm{~m}$ is 68.96 $\mathrm{Wm}^{-2}$ which is very high compared to that of the NE monsoon season. The daily total is very high and positive (table 3). These features are clearly attributed to the rise in incoming global solar radiation after the monsoon and drying up of soil at all depths (table 2). Cloudiness also changes the flow of heat into the soil. The typical days selected for study in the pre-monsoon and winter seasons are marked by cloud free skies. Less clouding during the day leads to a higher influx of heat into the soil. The thermal conductivity of the wet soil is high when compared to the dry soil. Diurnal pattern in the wet seasons follows a more irregular pattern than in dry seasons.

The mean diurnal soil heat flux curve in winter shows that the maximum is less pronounced than in the pre-monsoon season (figure 2b). For the soil layer $0-0.05 \mathrm{~m}$, the mean soil heat flux reaches maximum value of 107.12 and 101.00 $\mathrm{Wm}^{-2}$ around noon in pre-monsoon and winter, respectively. The corresponding standard deviations are 10.86 and $8.45 \mathrm{Wm}^{-2}$. The $24 \mathrm{~h}$ sum (453.53 $\mathrm{Wm}^{-2}$ for the layer $0-0.05 \mathrm{~m}$ ) and the diurnal amplitudes are also found to be very high when compared to monsoon seasons. Table 3 provides a seasonal comparison of mean diurnal soil heat flux amplitude and daily total. In both winter and pre-monsoon seasons, the soil heat flux changes its direction of flow around $7 \mathrm{~h}$ in the morning and $19 \mathrm{~h}$ in the evening.

Kelkar et al. (1980) measured the soil heat flux in Pune black cotton soil in different seasons. They showed that for the period June-February, the highest daily flux into the soil is in the postmonsoon season (October). In winter also, a small amount of heat goes into the soil. The reverse flow takes place on rainy days in the monsoon seasons. In this study also, net negative soil heat flux is observed in NE monsoon.

Tessy Chacko and Renuka (2002) studied the diurnal variation in soil heat flux on a wet and dry day in the year 2000. They found that the diurnal variation of heat flux is influenced by soil moisture and incoming solar radiation. They also concluded that in dry days, the net flow of heat is directed into the soil and in rainy days, the reverse takes place.

\subsection{Heat storage estimates and surface soil heat flux}

Energy balance studies require knowledge of the heat flux at the soil surface $\left(G^{*}\right)$. This flux is determined by summing the heat flux at a reference depth $(z)$ some centimeters below the surface and the rate of change of heat storage in the soil above $z$ (Ochsner et al. 2007). The rate of change of heat storage or heat storage in short $(\Delta S)$ is calculated from the soil volumetric heat capacity $\left(C_{s}\right)$ and temperature using equation (5).

Heat storage terms are estimated for $24 \mathrm{~h}$ on all days selected for study. It is found that the heat storage term varies in the range $20-80 \%$ of the soil heat flux. Figure 3 shows the mean energy storage for the $24 \mathrm{~h}$ period during pre-monsoon 2008. Mean surface soil heat flux calculated from the energy storage is also shown in the figure. The energy storage per hour is maximum during noon time. Also, it is high during pre-monsoon and winter when compared to the monsoon seasons. Maximum mean heat storage of $50.25 \mathrm{~W} / \mathrm{m}^{2}$ with a standard deviation of $7.47 \mathrm{~W} / \mathrm{m}^{2}$ is observed in pre-monsoon season. During night time, the heat storage becomes negative indicating energy loss from the soil.

Similarly the mean soil heat flux at the surface for pre monsoon, winter, SW monsoon and NE monsoon is obtained. The diurnal variation of mean ground heat flux for the selected days in the four seasons is shown in figure 4 . The estimated ground heat flux show diurnal variations similar to that observed on the layer $0-0.05 \mathrm{~m}$ in all seasons. The maximum and minimum surface heat fluxes of 157.37 and $-40.23 \mathrm{Wm}^{-2}$ are observed in the premonsoon and NE monsoon seasons, respectively. The standard deviations are 11.68 and $6.93 \mathrm{Wm}^{-2}$, respectively. The amplitude of the mean soil heat flux curve is also found to vary during the premonsoon season $\left(95.83 \mathrm{Wm}^{-2}\right)$. Seasonal variation

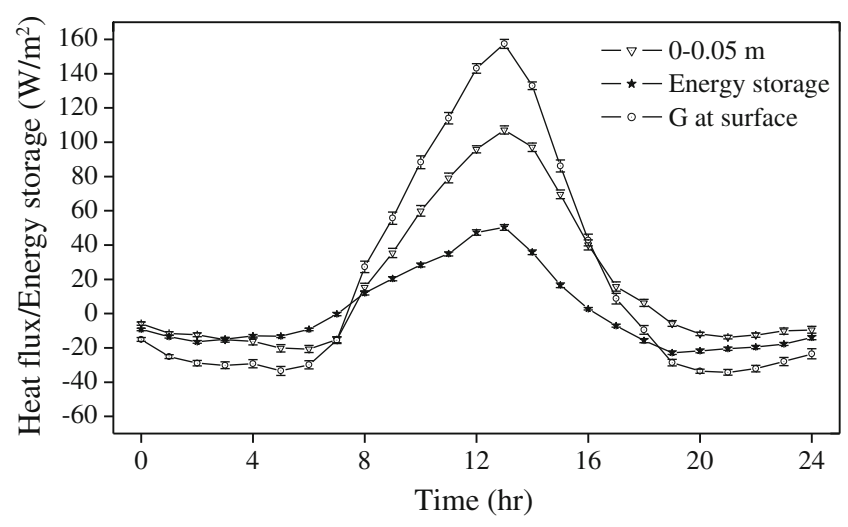

Figure 3. Diurnal variation of mean energy storage and soil heat flux at $0.05 \mathrm{~m}$ depth and surface during pre-monsoon 2008 . 


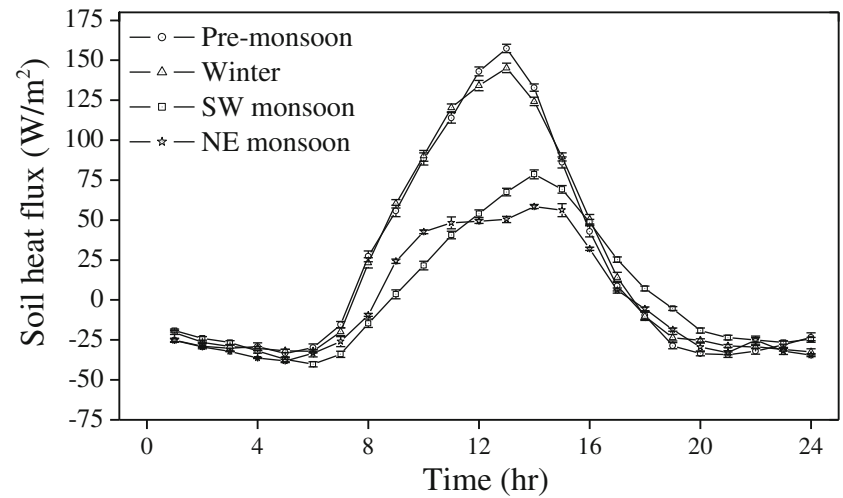

Figure 4. Diurnal variation of mean soil heat flux at the surface estimated from the $0.05 \mathrm{~m}$ depth measurements on selected days from each season, 2008.

of mean amplitude of surface heat flux is also presented in table 3.

Anandakumar et al. (2001) in their study on the soil thermal properties at Kalpakam, estimated the soil heat flux at the surface from 0.02 and $0.10 \mathrm{~m}$ measurements for a wet and a dry day. Both the estimated values were in close agreement to each other for all the days they studied. They also found that the soil heat flux at the wet soil surface is lower than that at the dry surface.

\subsection{Day time surface energy balance closure}

The knowledge of energy budget across the soilair interface is of primary importance in understanding the exchange process across the soil-air interface and mechanism at the Earth's surface, which are essential for forecasting climate. Two contrasting case studies for pre-monsoon (dry soil surface condition) and SW monsoon (wet soil surface condition) are presented in figure $5(\mathrm{a}$ and $\mathrm{b})$, respectively.

The early morning condition on the pre-monsoon day was a little humid, but the soil surface was dry. The mean soil temperature rose rapidly from $33.1^{\circ} \mathrm{C}$ during morning hours (at $0800 \mathrm{~h}$ ) to reach a maxima of $43.8^{\circ} \mathrm{C}$ by $1400 \mathrm{hrs}$ local time. The average value of albedo obtained was 0.26 . Albedo also plays a major role in the energy balance of the Earth's surface, as it defines the rate of the absorbed portion of the incident solar radiation (Sumithranand et al. 2009). The day time mean sensible $(H)$, latent $(L)$ and surface heat fluxes $\left(G^{*}\right)$ along with the net radiation $(R)$ for premonsoon 2008 is shown in figure 5(a). In the morning hours, it can be observed that the latent heat was about three times higher than sensible heat flux and the Bowen's ratio was 0.38. Around the local noon, the mean sensible and latent heat fluxes
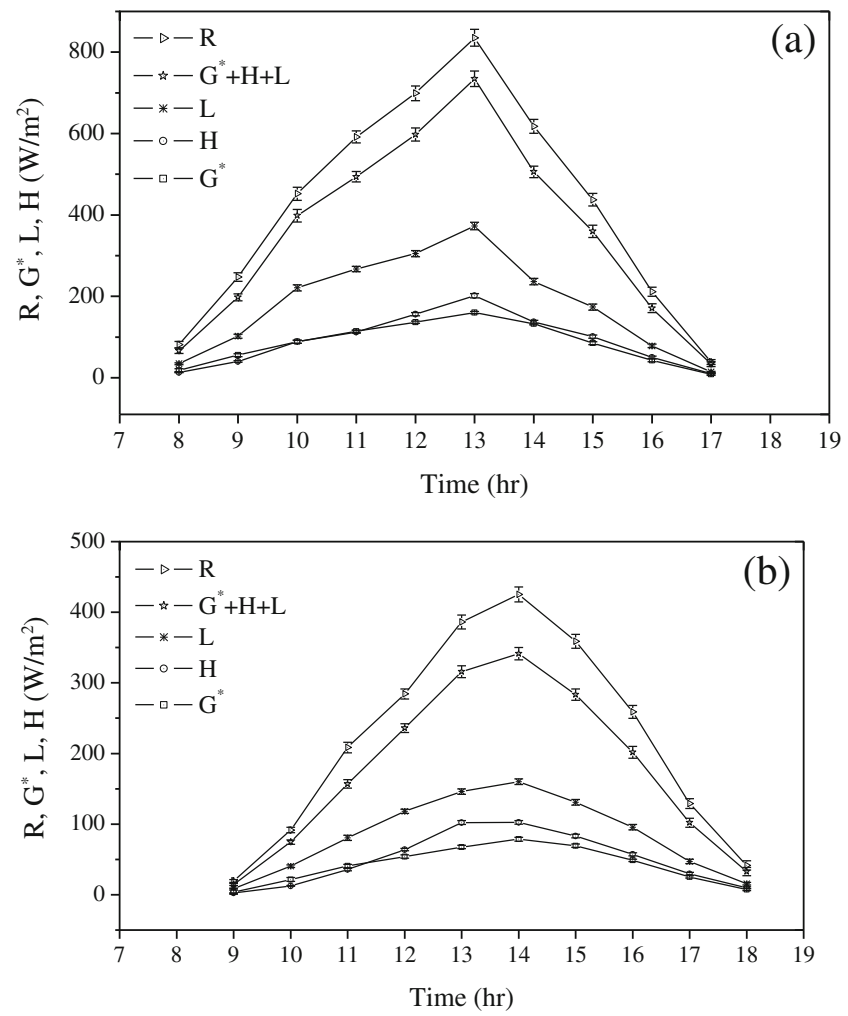

Figure 5. Estimates of mean day time surface energy balance components on (a) dry season and (b) on wet season.

were about 24.1 and $44.6 \%$ of the net radiation, respectively.

The average Bowen's ratio obtained during premonsoon 2008 was 0.515 with standard deviation of 0.09 , thus indicating that there was a considerable evaporation from the surface. Despite a dry soil surface, the average latent heat flux was very high, about $373.03 \mathrm{Wm}^{-2}$ at $1400 \mathrm{~h}$. This is because of high surface temperature and less relative humidity. In the afternoon, the evaporation from the surface is reduced as the temperature drops and relative humidity rises. The average Bowen's ratio at $1700 \mathrm{~h}$ was about 0.712 . The day time mean energy balance components estimated during premonsoon accounts for only about $83.73 \%$ of the net radiation. It is found that the mean value of the day time energy budget closure $(\varepsilon)$, defined as the ratio of the sum of the sensible and latent heat fluxes $(\mathrm{H}+\mathrm{L})$ to the available energy $\left(R-G^{*}\right)$ is about 0.795 . The maximum and minimum values of mean day time energy balance components and their standard deviations during pre-monsoon and SW monsoon seasons are presented in table 4 .

The early morning condition during SW monsoon was wet due to the rainfall of previous days. Near the surface, the air was also very humid. The solar radiation penetrates considerably after $0800 \mathrm{~h}$ for the surface warming so that positive value of $G^{*}$ is obtained only from 0900 hrs. The mean soil 
Table 4. Maximum and minimum values of mean day time surface energy balance (SEB) components and their standard deviation for pre-monsoon and $S W$ monsoon seasons.

\begin{tabular}{|c|c|c|c|c|c|c|c|c|}
\hline \multirow[b]{2}{*}{ SEB components $\left(\mathrm{W} / \mathrm{m}^{2}\right)$} & \multicolumn{4}{|c|}{ Pre-monsoon } & \multicolumn{4}{|c|}{ SW monsoon } \\
\hline & Maximum & $\mathrm{SD}$ & Minimum & $\mathrm{SD}$ & Maximum & $\mathrm{SD}$ & Minimum & $\mathrm{SD}$ \\
\hline Net radiation $R$ & 835.25 & 92.85 & 38.65 & 27.33 & 425.25 & 19.51 & 47.27 & 16.39 \\
\hline Surface heat flux $G^{*}$ & 160.20 & 11.68 & 8.72 & 6.64 & 78.67 & 12.31 & 3.57 & 3.82 \\
\hline Surface heat flux $G_{c}$ (Gao's method) & 224.29 & 17.42 & 12.26 & 7.01 & 142.77 & 19.45 & 6.88 & 4.12 \\
\hline Latent heat flux $L$ & 373.03 & 41.47 & 14.33 & 7.39 & 160.18 & 17.81 & 8.78 & 2.68 \\
\hline Sensible heat flux $H$ & 201.43 & 22.39 & 10.21 & 5.27 & 102.52 & 11.39 & 2.35 & 0.72 \\
\hline
\end{tabular}

surface temperature rose to attain a maximum of $33.6^{\circ} \mathrm{C}$ by $1400 \mathrm{~h}$ local time. The average value of surface albedo was 0.19 , comparatively lower than that on the pre-monsoon day. The decrease of surface albedo with wetness of the surface was reported by Sumithranand et al. (2009) and Roxy et al. (2010).

The mean day time sensible, latent, and surface heat fluxes along with the net radiation for SW monsoon is shown in figure $5(\mathrm{~b})$. In the morning hours, it can be observed that the latent heat was about four times larger than sensible heat flux and the Bowen's ratio was 0.268. Around the local noon, mean sensible and latent heat fluxes were about 24.1 and $37.7 \%$ of the net radiation, respectively. The average Bowen's ratio obtained during SW monsoon was 0.54 with a standard deviation of 0.06 . The Bowen's ratio at $1700 \mathrm{hrs}$ was about 0.641. The ground heat flux and sensible heat flux were of comparable magnitudes on both the days. The Bowen ratio obtained falls in the range obtained by the earlier researchers (Lewis 1995; Jegede et al. 2001; Jegede 2002; Oladosu and Sumonu 2011). The day time mean energy balance components estimated during SW monsoon accounts only about $79.13 \%$ of the net radiation. It is found that the mean value of the energy budget closure is about 0.742 .

Heusinkveld et al. (2004) analyzed the surface energy balance for a sandy desert. A model neglecting vertical soil water movement will generate a reasonable estimation of energy budget closure for a dry hot desert where $W$ is extremely low (Gao et al. 2007). So it is not a surprise that energy balance closure was found to be very good at the site of Heusinkveld et al. (2004). Unland et al. (1996) examined surface flux measurements and model output at a semi-arid Sonoran Desert site, and their results show that the energy balance closure was found to be good.

Oladosu and Sumonu (2011) studied the surface energy budget over a humid tropical West African subregion using eddy covariance and Bowen ratio methods during February/March and July 2007. The mean closure was 92.21 and $80.72 \%$ for February/March and July, respectively. The results
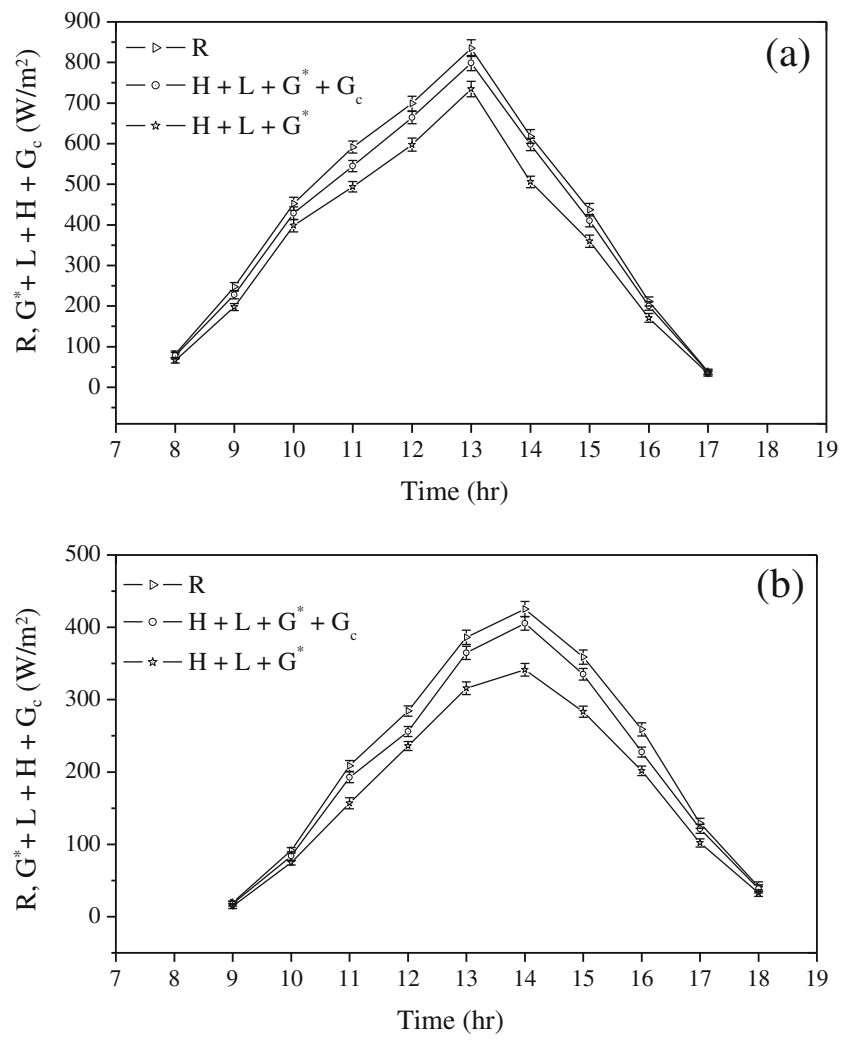

Figure 6. Estimates of sum of mean day time surface energy balance components (Gao 2005) and net radiation on (a) dry season and (b) wet season.

showed that minimum closures were obtained when the latent heat flux were highest. This occurred mainly during wet periods. In this study also, minimum energy balance closure is obtained on wet day.

The results obtained in the above study imply that if the vertical soil water movement is neglected in the calculation of surface soil heat flux $\left(G^{*}\right)$, a significant energy imbalance will be encountered for bare soils with considerable soil moisture where the vertical soil water movement is considerable. In the study site the daily water flux density was found to be positive even on the wet day. Therefore soil surface heat flux determination method proposed by Gao (2005) given in equation (7) is used. The maximum and minimum values of the mean 
surface soil heat flux calculated by Gao's method are presented in table 4 along with the standard deviations for the two seasons. Estimates of sum of mean day time energy balance components (Gao 2005) and mean net radiation in dry season, pre-monsoon 2008 and in wet season, SW monsoon 2008 are shown in figure 6 . It is found that the surface energy balance closure (SEBC) is improved to 0.921 and 0.887 on dry and wet days respectively. The standard deviations of mean day time surface energy balance closure are 0.016 and 0.019 for dry and wet seasons, respectively.

Gao (2005) examined the soil heat flux for a Tibetan short-grass prairie site and found that the energy imbalance reaches $30 \%$. He re-examined the calculation of soil heat flux at the site by considering soil vertical water movement, resulting in better surface energy balance closure of 0.90 . Eventhough the later method still does not completely satisfy the energy closure, it has significantly improved the earlier results. Theoretically, $\varepsilon$ should be very close to 1.0 and the lack of energy balance closure has also been reported in many studies (Nie et al. 1992; Smith et al. 1992; Oladosu and Sumonu 2011). They pointed out that the uncertainty in locally estimated sensible and latent surface heat fluxes may be about $10-20 \%$ of the net radiation.

\section{Conclusions}

- The soil temperature data collected at one hour intervals for the year 2008 using hydrometeorological data acquisition system installed at Astronomical Observatory is used to deduce the diurnal variation in soil heat flux.

- The diurnal variation is characterized by a crossover from negative to positive values in the early morning occurrence of maximum around noon and return to negative values in the late evening.

- The amplitude of the diurnal heat flux is found to be high during winter and pre-monsoon seasons as compared to monsoon seasons. During NE monsoon, the daily total heat flux is found to be negative.

- Daytime surface energy balance at the surface on wet and dry days is investigated. The average Bowen's ratio during the wet and dry days were 0.523 and 0.508 , respectively indicating that considerable evaporation takes place at the surface.

- The traditional method of calculating soil heat does not account for the influence of soil vertical water movements on soil surface temperature and on soil heat flux. Although it can be used for dry desert soils, where the vertical water movement is insignificant, it significantly underestimates the soil heat flux for bare soils with considerable wetness where the vertical water movement is significant.

\section{Acknowledgements}

The authors thank the Director and Staff members of the India Meteorological Department, Thiruvananthapuram for providing the data required for this work. They are grateful to the anonymous reviewers for their thorough reviews, helpful comments and suggestions.

\section{References}

Abraham T R S and Renuka G 2005 Heat storage at subsurface soil and microclimate at Thiruvananthapuram, India; Indian J. Radio Space Phys. 34 274-280.

Anandakumar K, Venkatesan R and Prabha T V 2001 Soil thermal properties at Kalpakkam in coastal south India; Proc. Indian Acad. Sci. (Earth Planet. Sci.) 110(3) 239-245.

Braud I, Noilhan J, Bessemoulin P and Mascart P 1993 Bare ground surface heat and water exchanges under dry conditions: Observations and parameterization; Bound.-Layer Meteorol. 66 173-200.

Chowdhury A, Das H P and Chivate V R 1993 Energy balance evaluation in Bengal gram (Cicer arietinum L.) grown in a sub-humid climate; Mausam 44(3) 277280 .

Cobos D R and Baker M B 2003 In situ measurement of soil heat flux with the gradient method; Vadose Zone J. 2 589-594.

DeBruin H A R 1982 The energy balance of the earth's surface: A practical approach; Royal Netherlands Meteorological Institute, Netherlands.

DeBruin H A R and Holtslag A A M 1982 A simple parameterization of the surface fluxes of sensible and latent heat during daytime compared with Penman-Monteith concept; J. Appl. Meteorol. 21 1610-1621.

Gao Z 2005 Determination of soil heat flux in a Tibetan short-grass prairie; Bound.-Layer Meteorol. 114 165-178.

Gao Z, Fan X and Bian L 2003 An analytical solution to onedimensional thermal conduction-convection in soil; Soil Sci. 168(2) 99-107.

Gao Z, Chen G T J and Hu Y 2007 Impact of soil vertical water movement on the energy balance of different land surfaces; Int. J. Biometeorol. 51(6) 565-573.

Garratt J R 1992 The Atmospheric Boundary Layer; Cambridge University Press, Cambridge.

Heitman J L, Horton R, Sauer T J, Ren T S and Xiao X 2010 Latent heat in soil heat flux measurements; Agric. For. Meteorol. 150 1147-1153.

Heusinkveld B G, Jacobs A F G, Holtslag A A M and Berkowicz S M 2004 Surface energy balance closure in an arid region: Role of soil heat flux; Agric. For. Meteorol. 122 21-31.

Horton R and Wierenga P J 1983 Estimating the soil heat flux from observations of soil temperature near the surface; Soil Sci. Soc. Am. J. 47 14-20.

Hsieh C I, Huang C W and Kiely G 2009 Long-term estimation of soil heat flux by single layer soil temperature; Int. J. Biometeorol. 53 113-123. 
Jegede O O 2002 Observation of daytime surface energy balance in cloudy tropical conditions at Ile-Ife, Nigeria; Mausam 53(3) 359-366.

Jegede O O, Foken Th and Bslogun A A 2001 Bowen ratio determination of sensible and latent heat fluxes in a humid tropical environment at Ile-Ife, Nigeria; Mausam 52(4) 669-678.

Kelkar R R, Chivate V R and Dubey R C 1980 Observations of soil heat flux at Pune using a heat flux plate; Mausam 31(1) 151-156.

Kumari Manju and Sharma O P 1987 The estimation of surface fluxes from heat balance equation for the city of Delhi; Mausam 38 67-72.

Langer M, Westermann S, Muster S, Piel K and Boike J 2011 The surface energy balance of a polygonal tundra site in northern Siberia - Part I: Spring to fall; The Cryosphere 5 151-171.

Lewis J M 1995 The story behind the Bowen ratio; Bull. Am. Meteor. Soc. 76(12) 2433-2443.

Liebethal C and Foken T 2007 Evaluation of six parameterization approaches for the ground heat flux; Theor. Appl. Climatol. 88 43-56.

Menon P A and Rajan C K 1989 Climate of Kerala (Cochin: Classic Publishers).

Nie D, Kanemasu E T, Fritschen L J, Weaver H L, Smith E A, Verma S B, Field R T, Kustas W P and Stewart J B 1992 An intercomparison of surface energy flux measurement systems used during FIFE 1987; J. Geophys. Res. 97 18,715-18,724.

Ochsner T E, Sauer T J and Horton R 2007 Soil heat storage measurement in energy balance studies; Agron. J. 99 311-319.

Oladosu O R and Sumonu L A 2011 Investigation of surface energy budget over a humid tropical site at Ile-Ife, Nigeria: A comparison of eddy covariance and Bowen ratio methods; Indian J. Radio Space Phys. 40 $37-44$.

Oladosu O R, Jegede O O, Sunmonu L A and Adediji A T 2007 Bowen ratio estimation of surface energy fluxes in a humid tropical agriculrtural site, Ile-Ife, Nigeria; Indian J. Radio Space Phys. 36 213-218.

Payero J O, Neale C M U and Wright J L 2005 Estimating soil heat flux for alfalfa and clipped tall fescue grass; Appl. Eng. Agric. 21(3) 401-409.

Prasada Rao G S L H V 2003 Agricultural Meteorology; Kerala Agricultural University Press, Thrissur.

Roxy M S, Sumithranand V B and Renuka G 2010 Variability of soil moisture and its relationship with surface albedo and soil thermal diffusivity at Astronomical Observatory, Thiruvananthapuram, south Kerala; J. Earth Syst. Sci. 14 507-517.

Sivadas T K 2007 Sensors and Measurement Systems for Environmental, Marine, Fisheries and Agricultural Applications (Cochin: Central Institute of Fisheries Technology).

Smith E A, Hsu A Y, Crosson W L, Field R T, Fritschen L J, Gurney R J, Kanemasu E T, Kustas W P, Nie D, Sheuttleworth W J, Stewart J B, Verma S B, Weaver H L and Wesely M L 1992 Area averaged surface fluxes and their time-space variability over the FIFE experimental domain; J. Geophys. Res. 97 18,599-18,622.

Sumithranand V B, Roxy M S and Renuka G 2009 Variability of surface albedo with soil moisture and soil temperature at Astronomical Observatory, Thiruvananthapuram; Ultra Sci. 21(1) 63-66.

Tessy Chacko P and Renuka G 2002 Temperature mapping, thermal diffusivity and subsoil heat flux at Kariavattom of Kerala; Proc. Indian Acad. Sci. (Earth Planet. Sci.) 111(1) $79-85$.

Tessy Chacko P and Renuka G 2008 Thermal diffusivity of soils in iso-hyperthermic temperature regime by harmonic analysis; Indian J. Radio Space Phys. 37 360-365.

Unland H E, Houser P H, Shuttleworth W J and Yang Z L 1996 Surface flux measurement and modeling at a semi-arid Sonoran desert site; Agric. For. Meteorol. 82 119-153.

Viswanadham Y 1972 Studies on radiation balance at a tropical station; Pure Appl. Geophys. 97(1) 183-213. 